\title{
Linkage Analysis among the Real Estate Tax, Real Estate Investment and Real Estate Price
}

\author{
Lin Xu \\ Urban Vocational College of Sichuan, Chengdu, Sichuan, China, 610101
}

Keywords: Real Estate Tax; Real Estate Investment; Real Estate Prices; Linkage

\begin{abstract}
In this paper, through the construction of VAR model, the variance decomposition method and the impulse response method are used to study the linkage relationship between real estate tax and real estate investment and real estate price, so as to find out the relationship among the three to solve the current problems of Chinese real estate market industry to provide data based on the promotion of Chinese real estate market industry, stable and healthy development.
\end{abstract}

\section{Introduction}

Since the reform of housing system has been implemented in China, the domestic real estate market has developed in an irresistible situation, which has played an important role in stimulating the growth and domestic demand of our national economy. At the same time, Chinese real estate market shows irrational blind growth phenomenon, high real estate prices attract a lot of social resources blindly into the real estate industry, not only increased the probability of financial risk, while too high prices and ordinary the affordability of buyers does not match, making the real estate industry has shrunk, in the long run, which for the stable development of Chinese social economy and the sustainable development of the real estate industry has many adverse effects. To this end, China has stepped up macro-control, hoping to use the real estate tax system and other policies to promote the real estate market stable and healthy development. However, the real estate tax policy is not perfect, in the implementation process there have been many problems, its real estate investment and real estate prices can have a favorable impact is also worth studying.

\section{The Construction of the VAR model}

The Source of the Data. This paper is based on data from 1999 to 2014 and real estate tax (ET) and real estate price (EP) and real estate investment (EI). The real estate tax mainly collected property tax, cultivated land occupation tax, Real estate prices for the collection of the total tax revenue; real estate prices are the average selling price of commercial housing as a data collection source, the statistical software is used EVIEWS7.2.

Metering Model. By constructing a VAR model, which includes the endogenous variables of ET, EP and EI, the relationship between these three factors is studied by means of stationary test and impulse response function analysis. Through the VAR model, we can understand and observe the dynamic interaction between several variables. The construction of the model is mainly to build all the endogenous variables in the system as a function of all the variable hysteresis.

The following is the most common vector autoregressive model formula:

$$
y_{t}=A_{1} y_{t-1}+\cdots A_{P} y_{t-p}+B_{1} x_{t}+\cdots+B_{t} x_{t-r}+\varepsilon_{t}
$$

Where the m-dimensional endogenous variable vector is $y t$; the d-dimensional exogenous variable vector is $\mathrm{xt}$; the parameter matrix to be estimated is $\mathrm{A} 1, \ldots, \mathrm{Ap}$ and $\mathrm{B} 1, \ldots, \mathrm{Br}$; endogenous variables and exogenous variables exist $\mathrm{p}$ and $\mathrm{r}$ lag Period; random perturbation term is expressed by $\varepsilon t$.

Test the Smoothness of the VAR Model. The premise of the VAR model is that the data should be stable, so it is a prerequisite to determine whether the time series data is smooth. This study mainly uses ADF unit root test method to examine the ET and EI and EP three elements of the 
smooth.

Analysis of the Covariance Test Results of the Model. The optimal hysteresis value in the VAR model is determined. If the value of $\mathrm{K}$ is high, the degree of freedom in the model will be greatly reduced, which will affect the validity of the model parameter estimation. However, if the K value is low, the error term will be seriously correlated The The article uses the AIC and SC to minimize this criterion to determine the range of $\mathrm{K}$ values. The following table shows the results of the optimal lag of the VAR model.

Table 1. The Result of the Optimal Lag of VAR Model

\begin{tabular}{ccccccc}
\hline Lag & LogL & LR & FPE & AIC & SC & HQ \\
\hline 0 & 34.53932 & NA & $1.57 \mathrm{E}-06$ & -4.852203 & -4.72183 & -4.879001 \\
\hline 1 & 79.25075 & 61.90813 & $6.86 \mathrm{E}-09$ & -10.34627 & -9.824777 & -10.45346 \\
\hline 2 & 82.04404 & 2.57842 & $2.45 \mathrm{E}-08$ & -9.39139 & -8.47878 & -9.578973 \\
\hline 3 & 126.9132 & $20.70885 *$ & $3.00 \mathrm{e}-10 *$ & $-14.90973 *$ & $-13.60600 *$ & $-15.17770 *$ \\
\hline
\end{tabular}

From the above test results which we can understand, 3 is its optimal lag. At the same time, combined with the results of this test, we can also understand that the time series data and cointegration test requirements are consistent, we have the data in Table 2 Johansen cointegration test.

From above we can see that if the original hypothesis of the cointegration relationship does not exist, then the probability of $\mathrm{P}$ is less than 0.05 , indicating that there is a cointegration relationship exists. In order to ensure that the pseudo-regression phenomenon does not occur, and can understand the real estate tax and real estate investment and real estate prices in three elements in a long time to maintain this balanced relationship, we combine the three elements of the data can create a VAR model. In addition, we need to estimate the root of the AR feature polynomial to verify the stability of the model. Figure 1 is the unit circle of the reciprocal of the AR characteristic root:

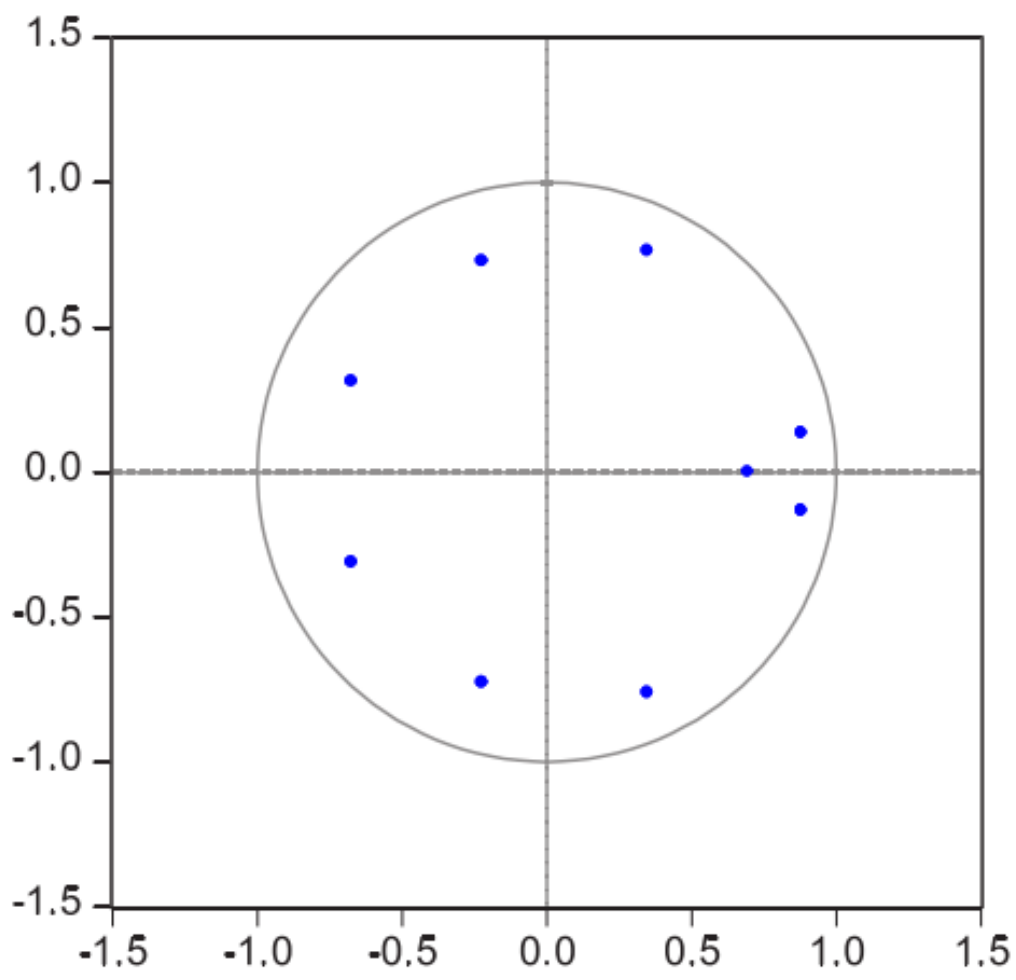

Fig. 1 The AR unit is represented by the unit number of the reciprocal of the root

From the above figure we can see that the reciprocal of all its roots is in the circle, which indicates that the model is smooth. 


\section{Validate the VAR Model}

Study on the Result of Impulse Response Function. Through the impulse response function we can clearly observe the changes in the error changes will be affected by the endogenous variables. In this paper, the corresponding impulse response function is constructed with VAR model. As shown in Figure 2 below:
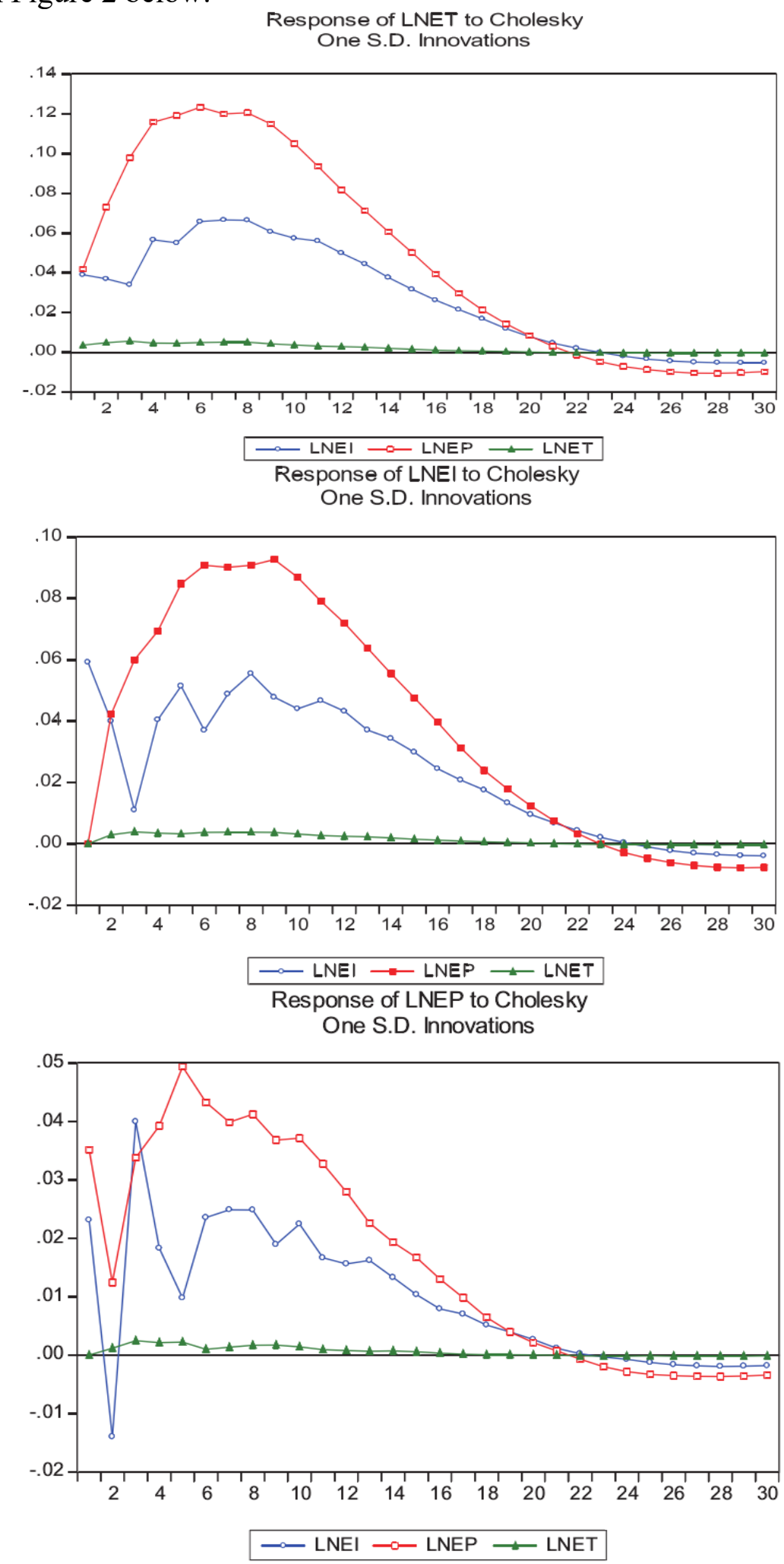

Fig. 2 The corresponding impulse response function

From the above chart on the reaction of ET which we can understand:

1) Impulse response in the real estate column changes, the first phase is about 0.4 , from 1 to 7 
these period values are showing a sudden change in the state, the seventh period when the value to the top value and then showed a gradual decline in the trend to 23 after the value becomes a negative impact. This shows that from a long time to analyze the words, the collection of real estate tax in the suppression of real estate investment has a certain role, but the effect is not very obvious, from a short time to see, then the collection of real estate tax will promote real estate investment. Analysis of this phenomenon should be the reason for the emergence of local governments in order to attract more industrial and commercial enterprises settled and thus low-cost supply of industrial land, in order to improve local revenue, and local officials forced by the impact of pressure often to investors promised to give preferential treatment of the financial system, which led to pre-real estate investment is too strong, but usually the next successor officials tend to make up for the financial expenditure is often increased real estate tax.

2) Impulse response changes in the real estate price column, the first period is 0.4 , from 1 to 7 these periods have shown a continuous upward trend and reached the top value in the seventh period, starting from the beginning of the seventh period of continuous Reduced, probably in the twenty-second period when turned into a negative response.

This shows that a short period of time to levy real estate tax for the suppression of house prices will not have a role in the fall, but a long time to levy real estate taxes will play a role in curbing the decline in house prices, but the effect is not very obvious. The reasons for this phenomenon are related to the adverse effects of the government system. The relevant systems of the state and local governments are usually delayed in the course of implementation. That is to say, before the government increases the real estate tax rate, the market It is prone to "looting", making the commercial housing in short supply, and then promote the housing prices continued to rise.

3) Real estate tax for their own response analysis, we can see from the figure, its impact in the first phase is very small, the impact is very small (has not more than 0.3 ), and finally even close to 0 , which means that real estate tax for Its own impact brought about by the response to the previous significant, to the latter part of the impact of approaching 0. Analysis of the "response to the EI" chart can be learned: First, the real estate price of the impulse response function is the first phase 0 , then began to rise until the 10th period to reach the top value, then began to decline until 23 period from the positive response turned into a negative response. This shows that in the short term to increase investment in real estate will make housing prices rise, but from a long time to analyze will lead to lower prices.

The result of this result may be: to keep rising prices will continue to attract a large number of investors into the capital, but the high prices are so that most ordinary buyers cannot afford housing, the final decline in demand, in addition, Real estate investment will make the market over the housing supply oversupply phenomenon, house prices will therefore decline. The real estate tax for real estate investment reaction is little change, mainly after the first rise to 0 , indicating that the current domestic real estate market is still the main investment and the policy system intervention is relatively small.

4) Analysis of the "response to the EP" a map can be the following conclusions: First, EI for the EP response is relatively large, from the beginning of 0.25 has been reduced to a negative response, but gradually increased from the second phase, become Positive response, but rose to the twenty-third period and became a negative response, said the increase in house prices in the initial stage will not form a phenomenon of real estate investment too much, most investors will be affected by psychological factors, so its will the region's housing prices to make an analysis of the market after the corresponding investment. However, if house prices have been rising, it is bound to let investors continue to expand, leading to the phenomenon of real estate investment is too busy.

From the above analysis we can see that in the long run, to keep rising higher prices will have an inhibitory effect on real estate demand; a short period of time the local government in the face of rising prices often develop and implement the corresponding real estate tax policy, but A short period of time in Chinese real estate industry to stimulate the pattern of economic development will not change, so if the real estate tax in a long time to suppress the decline in house prices, it will be the initial investor's psychological expectations have a negative impact and the adverse impact on 
Chinese economic development. Therefore, in the future for a long time, our government's real estate tax policy will not have a positive response to housing prices.

\section{Analysis of Variance Decomposition Results}

The VAR model can be used to analyze the dynamic characteristics of the model. In Table 2 below, the variance decomposition of VAR for 8 VARs of the three variables are obtained by EVIEWS7.2.

Table 2 Variance of EI, EP, ET

\begin{tabular}{|c|c|c|c|c|c|}
\hline & Period & S.E. & LEEI & LEPP & LMEI \\
\hline \multirow{8}{*}{$\begin{array}{l}\text { El variance } \\
\text { decomposition }\end{array}$} & 1 & 0.059203 & 100 & 0 & 0 \\
\hline & 2 & 0.083049 & 74.00424 & 25.87397 & 0.121788 \\
\hline & 3 & 0. 103114 & 49. 13815 & 50.63962 & 0.222231 \\
\hline & 4 & 0.130757 & 40.12188 & 59.66963 & 0.208491 \\
\hline & 5 & 0. 164129 & 35.27519 & 61. 55461 & 0.170201 \\
\hline & 6 & 0.191232 & 29.72:6: & 70.10992 & 0.16240 \\
\hline & $i$ & 0.216985 & 28. 14739 & 71. 69588 & $0.156: 3$ \\
\hline & 8 & 0.241716 & 27. 95306 & 71. $\$ 9612$ & 0.150823 \\
\hline \multirow{8}{*}{$\begin{array}{l}\text { EP variance } \\
\text { decomposition }\end{array}$} & 1 & 0.012077 & 30.18629 & 69.81371 & 0 \\
\hline & 2 & 0.016062 & 34.37355 & 65.56125 & 0.06520 \\
\hline & 3 & 0.069784 & 47. 78362 & 52.06093 & $0.15515=$ \\
\hline & 4 & 0.082157 & 39. 43591 & 60.38183 & 0.179265 \\
\hline & 5 & 0.096392 & 29.67827 & 70.13703 & 0.184692 \\
\hline & 6 & 0.108255 & 28. 26281 & 71.58222 & 0.154962 \\
\hline & $i$ & 0.118033 & z. 22236 & 71.63136 & 0.14328 \\
\hline & 8 & 0.127493 & 27.98511 & 71.87423 & 0.14066 \\
\hline \multirow{8}{*}{$\begin{array}{l}\text { ET variance } \\
\text { decomposition }\end{array}$} & 1 & $0.05: 296$ & 46. 36177 & $53.25: 67$ & 0.380562 \\
\hline & 2 & $0.10002 \mathrm{z}$ & 28. 88235 & 70. 76279 & 0.351856 \\
\hline & 3 & 0.14413 & 19. 45678 & 80.21894 & 0.32427 \\
\hline & 4 & 0.193162 & 19. 31728 & 80.41485 & 0.237871 \\
\hline & 5 & 0.233818 & 18. 78472 & 81.01516 & 0.199823 \\
\hline & 6 & 0.272459 & 19. 65275 & 80.16807 & 0.179179 \\
\hline & 7 & 0.305101 & 20.43614 & 79.39374 & 0.17011 \\
\hline & 8 & 0.334787 & 20.91669 & 78.91972 & 0.163592 \\
\hline
\end{tabular}

Note: S.E corresponds to the standard error for each variable.

By analyzing the variance table we can see that:

1) If we do not take into account the impact of real estate investment on its own changes, it can be determined that, as time goes by, the variance of variance in real estate prices will continue to increase until the eighth period, this time domestic real estate More than $17 \%$ of the changes in investment are from this, it also shows that real estate investment is very susceptible to house prices, if the price will rise and will not decline in the expected implementation of the continuous rise in housing prices will lead to more investors to invest. However, the real estate tax on real estate investment will not bring much impact.

2) Explore the impact of real estate prices fluctuate, the study of real estate prices will be affected by real estate investment and real estate tax impact. From the above table we can understand that the impact of real estate price changes on its own, the real estate investment changes in the most obvious impact, but the real estate tax changes will not bring real estate prices have a particularly significant impact.

3) Changes in real estate tax changes by the real estate price changes the most affected, even more than $8 \%$ of $78 \%$. At the same time, changes in real estate investment will also affect the changes in real estate tax and the first 8 also exceeded $20 \%$. This phenomenon shows that the trend of real estate tax policy by the real estate prices and real estate investment trends are relatively large, if a long time real estate investment and real estate prices have continued to decline, will affect the 
current economic development in China. Therefore, in the current situation of China is in a critical period of economic restructuring, the collection of real estate tax in the regulation of the real estate market is not significant.

\section{Conclusion}

In this paper, the interaction between ET, EP and EI is analyzed by VAR model, and the following analysis results are obtained:

1) In the long run, real estate tax in the suppression of real estate investment and housing prices continue to rise has a certain impact but little effect, and a short period of time real estate tax will also promote real estate investment and housing prices.

2) The impact of real estate investment and real estate prices is mutual and real estate prices will have a greater impact on real estate investment, indicating that the current real estate market speculative investment in China a large number of exist.

3) From a short time to analyze the real estate investment and the impact of both the housing prices are showing a positive correlation, but the long-term analysis is showing a negative correlation between the current domestic real estate markets in line with the high inventory phenomenon. Housing prices continued to rise and attracted a large number of amazing real estate investment, but too high prices and the general consumer spending power does not match, and then led to shrinking real estate demand, making the current domestic real estate industry in many cities there have been no market phenomenon, and then affected the pre-real estate investment, leading to lower investment.

4) Real estate tax policy will be affected by real estate investment and real estate prices, the use of macro - control to control Chinese real estate market effect is not obvious.

Combined with the above conclusions, I believe that to promote the healthy and stable development of Chinese real estate market, you can proceed from the following aspects: First, the state and the government should increase the implementation of efforts to develop and implement a series of policy systems, joint use of administrative means, financial means as well as financial means to achieve a smooth real estate market. Second, the relevant departments should be the current real estate market speculation behavior norms, strict implementation of the relevant penal system for the healthy and stable development of Chinese real estate market to provide effective protection. Thirdly, starting from the reform of "supply side", we will slowly change the economic development behavior of investment and development, optimize the resource allocation of capital and land, and promote the development of social economy in China with scientific and technological innovation.

\section{References}

[1] Zhou Ruiyang. Real estate-related tax on the impact of housing prices theory and empirical research [D]. East China Normal University .2015

[2] the first small Jing. Chinese real estate industry tax situation and reform [D]. Southwest University of Finance and Economics .2014

[3] Liu Yan. Government real estate regulation and control policy and housing price control effect [D]. Shanghai Normal University .2014

[4]. Duan Yanyan Tian Hua. Theoretical and Empirical Study on the Relationship between Real Estate Investment and Real Estate Price. Research on Productivity .2009.2

[5] Lai Yifei. Huang Rui, etc. Interest rate fluctuations, real estate investment and real estate prices associated model. Wuhan University Journal (Engineering) .2014 (01) 